\title{
J
}

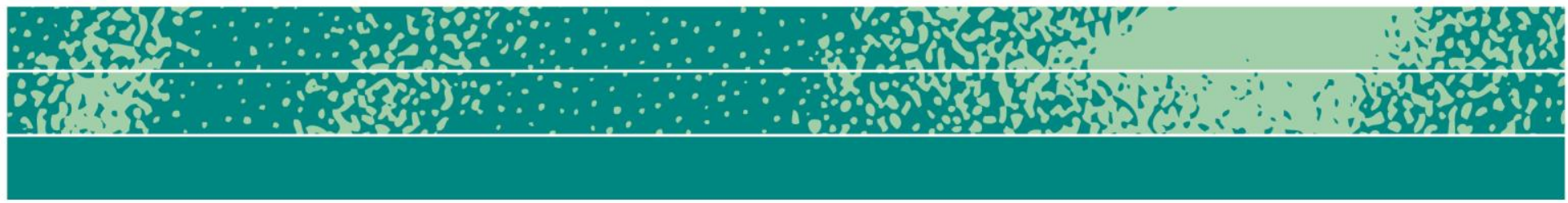

\section{Consistent Inconsistency in Fashion Magazines: The Socialization of Fashionability in Hong Kong}

Tommy Tse

\begin{abstract}
Fashion plays a significant role in the global creative industries and in urban social space, and has recently evolved from a peripheral topic to a valued interdisciplinary subject coined as "fashion-ology," investigating how fashion as an intangible and changeable meaning is systematically produced by and amongst different cultural intermediaries, and how it is cyclically diffused in society. As an exercise in understanding the conflictual notions of fashion in operation under the rubric of production inside a local fashion media organization, this study emphasizes how text and image in fashion representation can be multifarious and are intertwined with the commercial and capitalist logic of the fashion industry. This research supplements related ethnographic studies and discerns how industry practitioners actually negotiate fashion meanings and are constantly torn between encoding desirable (luxury) fashionability, while at the same time anticipating and serving different advertisers' interests.

Fieldwork data portray partly conflicting, partly consistent notions of fashion among different workers in the fashion media. The focus was: What shapes the collective interpretation and production of fashionability within a media organizational setting? The responses demonstrate the effect of advertising on fashion editorial pages and its major role in shaping fashionability, in addition to the contradictory rules guiding how
\end{abstract}

Page 1 of 26

JBA 5(1): 154-179 Autumn 2016

(C) The Author(s) 2016 ISSN 2245-4217

www.cbs.dk/jba 
media people strive to present a preferred face of luxury fashion in the magazine and why such an attempt was unsuccessful in this case.

\section{Keywords}

Creative labor, fashion, fashion magazines, Media and Cultural Studies, Hong Kong

\section{Encoding fashionability}

Fashion is ubiquitous as a social phenomenon. It has a significant role in the global marketplace as well as in creative industries. Although many still regard mainstream fashion as a hypocrisy that merely presents delightful and glittery images in the media, and advertising that triggers endless consumption (mostly by women)(Barnard 1996), in scholarly circles, the subject itself has evolved from a subaltern and frivolous domain to a much more important field across various disciplines, particularly in Sociology, Anthropology, Marketing, and Media and Cultural Studies, ${ }^{1}$ Now it even has a specific interdisciplinary home in "Fashion Studies," and a handful of dedicated academic journalsincluding Critical Studies in Fashion and Beauty, Fashion Practice: The Journal of Design, Creative Process and the Fashion Industry, Fashion Theory, and International Journal of Fashion Studies (Aspers and Godart, 2013, pp. 171-192). Simmel, Blumer and Kawamura have been particularly interested in investigating the interaction between individuals and institutions within the fashion system, depicting fashion as simultaneously "a form of imitation" and "a product of class distinction" (Simmel, 1957, p.m541, 544); as "a central mechanism in forming social order" in a modern world that can be found not just in apparel, but also "in operation in a wide variety and increasing number of fields" (Blumer, 1969, p. 285, 290); and as a "social phenomenon" (Kawamura, 2005, p. 108). From Kawamura's viewpoint, the progress of cultural globalization has dissolved the Eurocentric "old structure and boundaries" (ibid.), as modern designers from various cultural backgrounds are moving into the center of the fashion system that is destabilized by its diversified fashion contents "created peripherally" (ibid., p. 108). Kawamura also emphasizes the challenges traditional fashion magazines are facing due to newly germinated "street fashion magazines" (ibid., p. 106).

Trajecting beyond various conflicting notions of fashion and the debates about whether fashion is Eurocentric, this study-conducted between 2011 and 2013-investigates and describes how conflicting

\footnotetext{
${ }^{1}$ See, for example, Aspers and Godart 2013; Chevalier and Lu 2009; Crane 2000; Entwistle 2000; Kawamura 2005; Lea-Greenwood 2013; Mears 2014; Moeran 2015; Steele 2005; Wilson 2007.
} 
content published in a fashion magazine is the result of decision making characterized by contrasting opinions held by editors, journalists, advertorial copywriters, and ad sales executives, as they set about encoding a desirable (luxury) fashionability to strengthen an aspired positioning of the magazine, and balancing various advertisers' interests and advertising revenues. It explicates fashion not as a consistent, definitive, and fixed idea, but as a collection of institutions, with an attendant set of personnel, objects, and practices in the complicated process of encoding fashionability. It focuses on apprehending the nuanced mechanisms of decision-making in a fashion print media organization in Hong Kong with its publication circulating across Greater China, while seeking to create a substantial case for the social construction of fashion, which can also be applied to and compared with those in other sociocultural contexts (Moeran 2015).

The aforesaid shifts in the conceptions of fashion have engendered it as a constructor of discourses across diverse classes and genders. The potency of the fashion media in psychological and behavioural steering of consumers is particularly evident in women's magazines, in which "represented fashion" (Jobling, 1999, p. 2) manifests images that pander to commercial or ideological pursuits. Magazine covers, often laden with names of designers, photographers and models, reflect the commercial intent of publishers curtained behind the more ostensible cultural contents (Moeran, 2015, p. 33); they also resonate underlying social and cultural norms through fashion photography. As an instrumental means of objectifying "sex, gender, race, class, the politics of consumption and pleasure" (Jobling, 1999, p.3), fashion photography reaches into individuals' consciousness, leaving imprints of "self-contained, sexual or identificatory fantasies" (ibid., p. 10). Such fantasies go as far as to mould readers' consumption patterns by indicating the purchase of fashion items as a channel for asserting one's "public persona" (Moeran, 2015, p. 36). Through this process, the fashion media create and propel "hyperreality" (Jobling, 1999, p. 5), as coined by Baudrillard; ultimately, what compose an entirety of the photographs' meanings and establish text-to-photograph relationships are intra-textual layers within fashion photographs (ibid., p. 62). In The Fashion System, Barthes also argues that fashion meanings are not derived from the physical representation of garments, but are created in and through fashion media under an intermix of social, aesthetic and economic factors that ideologically produce "verbal and iconic forms of representations" (as cited in Jobling, 1999, pp. 9-10). Entwistle postulates that fashion contextualizes human bodies in culture, sets a discourse about them, and navigates the way they are perceived and adorned. In this respect, fashion magazines play a significant role in not only promoting certain looks and products, but also, more importantly, in representing an "abstract idea and aesthetic discourse" (Entwistle, 2000, p. 237) for consumers. By perceiving fashion as both "discourse and practice" and revitalising the "social and 
identifiable" role of the human body, cultural intermediaries such as fashion journalists and editors are pivotal in the producer-consumer chain, directing consumers' daily fashion choices (ibid., p. 238).

Some concrete examples of how the media construct and produce our modern identities (Kellner, as cited in Massoni, 2004, p. 49) are shown below. In her study of the relationship between media representations, gender socialization, and occupational aspirations, Massoni (2004, p. 49) claims that for girls and women in particular, magazines inexplicitly direct readers' everyday behaviour and thought through textual and visual contents. Crane contends that, fashion acts as a "carrier of social agendas" (ibid., p. 24) that flexibly mold social identities beyond gender and social class, exposing fashion consumers to a wider field of options for defining their human experience and articulating their personae in a "hypersegmented" society (ibid., p. 11). Ferguson's notion of "feminist fallacy" challenges the assumed positive correlation between media imaging and female empowerment; and she critiques the media's inaccurate depiction of women's social positions in popular cultures, such as their continual portrayal of women as homemakers in contrast to their rising professional salience (Ferguson 1990, pp. 215-230). Recently, Wilson (2010, cited in Riello and McNeil, 2010, p. 531) also became more critical of the fashion industry and its derived meanings saturated in the media as merely reflecting our sexist, celebrity-mad, mass culture.

With a rampant increase in fashion publication advertising, the tension between "creativity" and "money" has become a recurring issue. This is highlighted by the way in which women's magazines have been subjected to the "pervasive invasion and takeover of editorial matter by advertising" (Moeran, 2015, p. 17). Oftentimes creative workers are "manipulated by the system for which they work" (ibid.) in pursuit of commercial success. The tension arises primarily from the "bedrock structural properties" (Caves, 2003, p. 74) of the creative industries, in which the structural requirements-in forms of contracts, joint ventures and so on-necessary for executing creative works simultaneously limit the creative autonomy of workers. Becker also acknowledges the incompatibility between artistic will and the rigidity of distribution systems-artists need a mechanism that allows others to access their work, appreciate it, and "repay the investment of time, money and materials in the work" (Becker, 1984, p. 93). Yet differences between the interests of the artists and those of intermediaries may hinder the effective distribution of creative work. Even in the presence of structural agreements between artists and intermediaries, however, uncertainties regarding the degree of contractual binding and means of renegotiation abound, resulting in an ongoing conflict between market power and creative talents (Caves, 2003, p. 82).

In the Hong Kong context, Leung's analysis of the dominant depiction of Western "'glamorous' women with supple lips, the 'femme 
fatale' look" in Cosmopolitan Hong Kong revealed a strong tendency toward adopting and perpetuating a foreign, upmarket, feminine image as an ideal in the fashion media communication process (Leung 2004, p. 430-432), even though conservative Chinese values still retain a strong hand in shaping local readers' fashion taste, and rendering a "toned-down image of sex and sexuality" represented in the female fashion magazine (ibid., p.435, 439). Although Barthes (1990) and Jobling (1999) also highlight the media as fashion's key mediator monitoring and generating its meanings, the symbolic message is sometimes implicit and subliminal, inevitably creating ambivalence and illogicality in fashion communication. Moeran (2015) further points out how most fashion magazines explicitly strive to sell their understanding and profiling of target readers to potential advertisers. By juxtaposing textual and visual messages, they shape the potential consumers' knowledge of fashion, although in most cases it is rather uncertain and difficult to synchronize the seemingly consistent market segment with the dissimilar brand images of a myriad of advertisers.

Based on the above discussions of various cultural intermediaries' power (particularly fashion media's) in generating fashion discourses, this study was designed to uncover the actual decision-making process of a fashion magazine in Hong Kong, revealing the difficulties for workers within the organization to produce and represent a linear set of fashion messages appealing to their "ideal readers" (as a discursive category), in accordance with the promises they made to their advertisers and the magazine's positioning described in the media sales kit.

\section{A history of Hong Kong fashion magazines: Participant observation at Stylistic $X$}

Through participant observation ${ }^{2}$, this empirical study investigates how the fashion print media in Hong Kong and global fashion publicists negotiate and insist on specific meanings among themselves in their work through written text and visual images (what I will here term encoding fashionability), and discuss how those meanings relate to larger historical, social, economic, and cultural trends in Euro-American fashion, its particular organizational and industrial setting, and the changing economic conditions in Asia. Through three local fashion editors with whom I was personally acquainted-one from an international title and two from two other local publications-I started exploring the

\footnotetext{
2 The participant study at Stylistic $X$ lasted for three months, where I served as an unpaid junior fashion reporter working for the Chinese language Hong Kong high fashion publication. This involved daily interaction with other employees, also with others such as freelance photographers and models, journalists with other international and local fashion titles, and fashion publicists. This enabled studying and analyzing their styles of operation and cooperation. In this article, all those concerned have been given pseudonyms.
} 
opportunity to work in any of these media as an unpaid participant observer in the local fashion industry. Eventually Fei, fashion editor of Stylistic $X$, was the first one to facilitate this opportunity for me during summer 2011. As it was difficult to gain access to the rather closed fashion media industry to conduct an academic participant study in general, I immediately seized the chance offered. Unpredictably, this semi-intentional step provided me with a chance to participate in and observe the particular production and negotiation of globalized fashion meanings in the Hong Kong context. As a high-end fashion magazine published across greater China, ${ }^{3}$ Stylistic $X$ turned out to be a magazine exhibiting the characters of both global monthly fashion titles (which mainly feature Euro-American luxury fashion and lifestyle news) and local weekly fashion magazines (which also feature local street fashion, celebrity gossip and news). Other ethnographic research published recently—such as Vangkilde's study of Hugo Boss (2011), Oliveira's of wine branding (2012) and Moeran's of various international fashion magazines (2015) - all take a micro approach when examining the industry's internal operations and institutional structures. Regardless of the different organizational scales and structures, my interviews with a dozen fashion editors working for other publications (Tse 2015) revealed that Stylistic $X$ unexpectedly demonstrated very similar traits in its fashion communication when compared to other fashion print magazines of different market positions in Hong Kong and mainland China, as well as those in other Asian countries such as Japan (Moeran, 2015).

Founded in 2006, Stylistic $X$ is a monthly magazine which has focused on discussions of high-end fashion, beauty, food, travel, and entertainment. It is published by Stylistic Limited, which has also circulated Youth Style since 2001, a street fashion magazine extremely popular among teenagers in Hong Kong, with a circulation of 100,000 copies per week. ${ }^{4}$ Youth Style aimed at keeping younger readers abreast of the latest and the most exciting social information without following any particular trends. In fact, Stylistic X first emerged from Youth Style as its original young readers became more conscious of world fashion and lifestyles over time. Stylistic $X$ was then launched to satisfy their evolved "needs" for luxury fashion. The " $X$ " in the title was intended to connote extraordinary, extravagant and excellent-the utmost version of Youth Style.

Stylistic $X$ publishes three different editions in Hong Kong, Taiwan, and mainland China with respective circulations of 50,000, 20,000 and

\footnotetext{
${ }^{3}$ About 70 per cent of the core content is identical, except the magazine is translated into simplex Chinese in its PRC edition, with rhetorical adjustments made for both its PRC and Taiwan editions.

4 See Census and Statistics Department, the Government of Hong Kong, SAR, 2015. In mid-2011 total population estimate was 7,071,600, among which the estimated number of people between the ages 10 to 24 was 1,206,300, and 25 to $39,1,646,700$.
} 
300,000 copies. Its reporters participate in various fashion weeks and interview many designers in order to introduce some of the latest features and brands that are (in their opinion) worth noticing. As a result, the Stylistic $X$ media sales kit claimed that it attracted a group of loyal readers, comprising administrative executives (27\%), artists or designers $(20 \%)$, and other professionals (31\%). 57 per cent were female and 43 per cent male. 75 per cent of them are aged between 25 and 39 and about 80 per cent claimed to have a monthly income in excess of $\mathrm{HK} \$ 20,000$ (approximately US $\$ 2,600$ ).

\section{Clashing masks of Stylistic X?}

The deeper organizational structure where fashion messages (conflicting with the aspired Stylistic $X$ positioning) were produced emerges after interview material had been rearranged and re-read. Class, economic influence, age, experience, cultural imperialism, and much else all exerted very significant influences on the production and diffusion of fashion. What emerged did not seem to match the desired image of luxury fashion the media organization aimed to encode and represent in its profiling of target readers to potential advertisers. Studying and interpreting the utterances of fashion industry insiders confirmed that the understandings and intended meaning(s) of fashion they expressed were not just occasionally inconsistent, but rather were consistently contradictory. In practical terms, this seemed to lead to a cognitively intricate and internally inconsistent fashion rhetoric being presented in the magazine.

\section{Writing Stylistic X}

Stylistic $X$ maintained a media sales kit setting out what it termed the "Stylistic $X$ ingredients" - the core content of the publication. To collectively and consistently present a sense of luxury fashion, it specified eleven categories which its journalists should constantly investigate and write about: cover stories, special features, fashion, beauty, lifestyle, trendy items, design and art, food, toys, events, and customized projects. In the summer of 2011, those with the specific job title of journalist at Stylistic $X$ were dedicated to clearly defined editorial and advertorial areas. ${ }^{5}$ For instance, junior reporter Ringo specialized in menswear features; Kris in women's wear features; and Kim in culture, lifestyle and food features. Fashion editor Fei was responsible for supervising all the junior reporters, coordinating photography, and interviewing for cover stories, as well as other fashion-related feature writing. Advertorial copywriter Timothy and junior advertorial copywriter Bee were responsible for all custom-made projects proposed by the advertisers and the relevant copywriting tasks. Senior advertorial copywriter Ginny

\footnotetext{
5 See Appendix 1.
} 
supervised all the other copywriters, coordinating custom-made projects with the ad sales team and the advertisers, and also took on copywriting related to beauty, jewelry, watches, and accessories. Tina and Tribecca were the senior editors responsible for supervising all the other editorial staff, as well as specializing in reporting news stories about beauty and skincare products.

Cello, the chief editor of Stylistic $X$, once told me that "Most of the time our [editorial] teammates don't formally talk about work...We don't have official meetings often, maybe only a quick, casual [topic] meeting once a month...The working style here is quite different"-thereby appearing to present a rather autonomous and decentralized organizational structure. In fact, the editorial supervision process was not perhaps as informal and decentralized as the chief editor described it. As the key decision maker, he constantly and tightly monitored the progress of all his editorial staff by phone, via email, and in person.

At the start of each calendar year (January), the chief editor and the managing editor-in-chief Sporty gathered all the journalists to set out the publication's editorial framework and alignment and discussed a rough plan for each issue of the magazine throughout the whole year. About a week after each month's editorial deadline (the $15^{\text {th }}$ of each month) for next month's issue, the editorial team had a one-hour topic meeting where the last issue's editorial work was discussed and the next issue's general content was decided, and topics to work on were assigned. Reporters were required to improvise relevant topics and verbally present their proposed content during that meeting. Usually, the chief editor and the managing editor-in-chief made the key editorial decisions immediately. Otherwise they made comments and suggested revisions of the topics presented, and also suggested new topics as necessary.

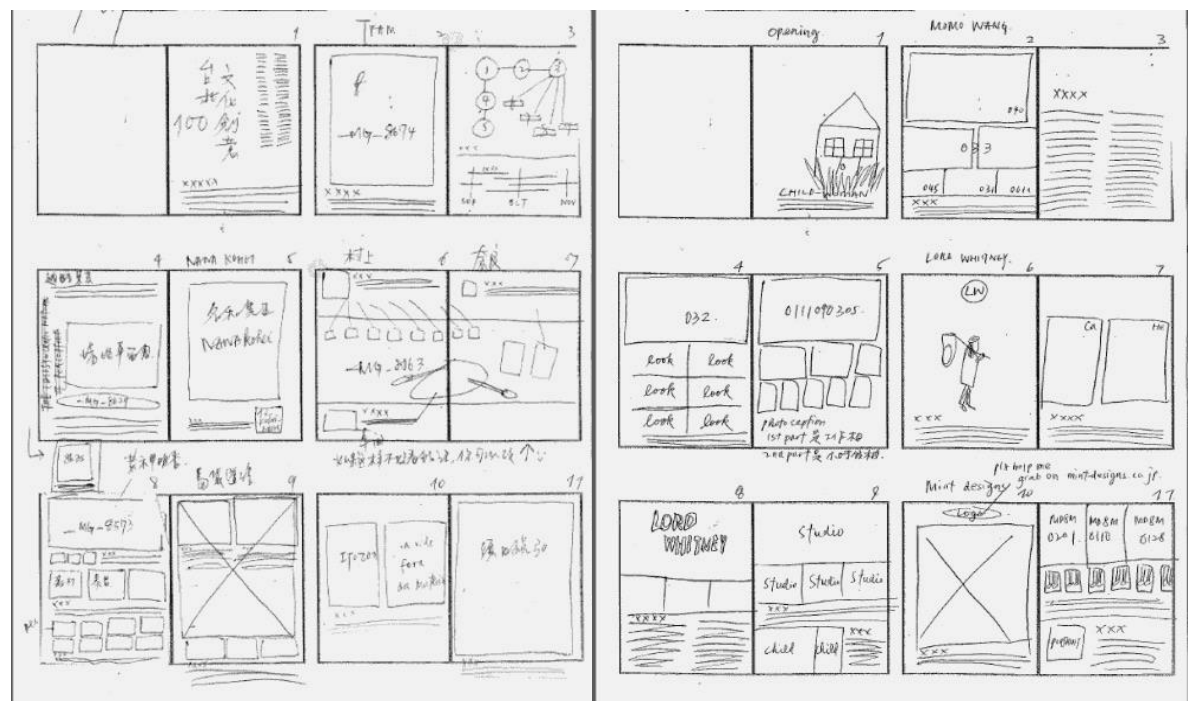

Figure 1. Example of draft editorial layout (by Kim). 
In the process of brainstorming editorial ideas, both journalists and ad copywriters at Stylistic $X$ were required to prepare their thoughts in both written and visual format, implying their nearly equal status in encoding fashion meanings. The rough editorial layouts (see Figure 1) were shown to the chief editor for evaluation. In our first individual meeting, Cello alerted me to pay close attention to the unique style of collaboration in a fashion magazine, because the staff all worked in a very individual, isolated mode. A chief editor should provide seasoned, critical suggestions to improve the ideas of the junior staff conceptually and help them to visually and verbally enhance the editorial appeal of their articles. On the one hand, individual journalists (fashion encoders/mediators) enjoyed a certain freedom in encoding fashionability according to their own knowledge, preferences, and impressions; on the other, they had to negotiate and align with the archetypal luxury fashion meaning of Stylistic $X$ with the chief editor as a helmsman who upheld a consistent fashion image delivered by the publication, in order to maintain a loyal readership and make it the advertisers' ideal tool to reach their target segments.

A typical afternoon editorial meeting lasted 75 minutes. In July, it began with Cello's critical comments on the editorial work of the latest issue, and continued with each editorial staffer sharing his or her ideas about topics for the annually most heavily advertised September issue that they were planning. These elicited immediate feedback from the chief editor. Cello's critique of the latest issue included some criticism of what he considered to be disorganized, uninteresting, unoriginal, and repetitive writing of mediocre quality, but the bulk of his criticism was directed at graphic and visual elements, which he felt were boring and unsurprising. More in tune with Jobling (1999)'s perspective, the main focus of Cello's criticism was on the iconic rather than the written content: rich fashion writing alone could not satisfy his expectations of "good" fashion editorial content. Cello did not, however, provide concrete examples to demonstrate what he regarded as organized, interesting, and original fashion coverage-at least not in these topic meetings.

Perhaps a feature idea presented by senior editor Tribecca at one such meeting can unravel this puzzle. Entitled "Old but Beautiful," the proposed feature was intended to exploit a sense of nostalgia about old Hong Kong. It was to feature the history and operations of long-standing local grocery stores and some of their representative products, interviews with some old product collectors, and (the most important part) the vintage housewares showcased and available at Lane Crawford, a local luxury department store. Cello's approval demonstrated an implicit logic in his editorial judgment: here he agreed that fashion coverage was not exclusively about the new and the modern; the old, the nostalgic, "Hong Kong culture," and everyday, ordinary items could also be beautiful and be made fashionable when stylistically presented alongside "true" luxury merchandize (by Lane Crawford). On other occasions, he categorically rejected such a standpoint, usually when there was no such linkage with 
an identified advertiser. Implicitly and explicitly, editorial staff were reminded to take potential advertisers' interests into consideration while writing fashion, and to feature a wide range of advertised products-not just in the advertising pages (including both print advertisements and advertorials) but also in editorial content. As a result, the traditional wall between editorial and ad sales teams has gradually been blurred, and the notion of creativity has evolved into a kind of technical mastery of advertiser-media relationships (Croteau, 2003).

Ringo at one point suggested a special feature entitled "Back to the Future." It would suggest that what a consumer bought this year could be used for another five to ten years without being regarded as outdatedseemingly the very antithesis of the entire fashion concept regarding ephemerality and cyclicality. He proposed treating "Five Dichotomies in Menswear Fashion" to be built around five opposing themes: everchanging versus eternal; simplicity versus complexity; thickness (fall and winter menswear) versus thinness (spring and summer menswear); must-have versus out-of-date; and safe and understated versus bold and playful. Cello suggested that while the five dichotomies idea sounded interesting, it was rather impractical due to its extensive scope (rather than its contradictory logic, such as "fashion is simultaneously everchanging and eternal"), and repeatedly asked Ringo if he really could manage three editorial features in a month. But Cello and the other editorial team members did not find Ringo's five dichotomies logically problematic at all, but rather normal and natural. Both Tribecca's and Ringo's cases resonate with Baudrillard's (2007) criticism that fashion is about the cyclical, illogical, and paradoxical exchanges of the old and the new, and a displacement of the signifier and the signified-the oldfashioned (the local grocery stores selling old products) is constantly and unquestionably presented as, and merged with, the fashionable (the renowned multi-label fashion retailer Lane Crawford selling designer vintage housewares). Specifically, Cello regarded the novel and nonrepetitive combinations of the old and the new as fashionable-the infinite interplay between the old signs and the new signifieds-leading to an endless stylization of everyday objects as fashion.

\section{Logics of visualizing Stylistic X}

Stylistic X's journalists, copywriters, and graphic designers often held opposing views about what constituted Barthesian iconic fashion. Senior graphic designer Jet, a rather thin young man who was self-named "Stylistic X Han Shuei Shuei" (shuei literally means "water" in Chinese), 6 and well-known for his bold fashion styles among his colleagues, repeatedly reminded me that Cello preferred small 6 to 8 point Chinese

\footnotetext{
6 The name was compatible with the mainland star fashion journalist of Marie Claire China Han Huo Huo-huo literally meaning "fire" in Chinese.
} 
characters, on he grounds that it made a layout more aesthetically pleasing. Culture and lifestyle reporter Kim disagreed, and suggested that Cello's perception that only very small (Chinese) fonts looked aesthetically pleasing (and stylish) was wrong. In Jet's viewpoint, the power of Stylistic $X$ or any other high-end fashion magazines lay in its visual rather than textual communication, and that was how he believed a typical contemporary fashion magazine reader would be mesmerized and taught about luxury aesthetics. "It also depends on how skillful the graphic designer is in typesetting," suggested women's fashion reporter Kris-a twenty-something with an asymmetrical and stylish crop hair, slender torso and white skin, wearing light makeup, a beige light-weight dress, dark colour cardigan and delicate silver accessories-adding, in an indirect critique of Jet's logic, that in such a small point readers would not be able to read the content clearly and the blocks of words would be diminished as part of the total layout. Kim took the graphic style of The Ming, a well-known lifestyle magazine in mainland China, as an example to substantiate her point that larger Chinese characters can look stylish, although she also emphasized her impression that Cello cared primarily about the visual aspect of the magazine.

Jet later criticized my own feature entitled "The Fashion Network: Fashion Marketers Outside and Inside." He was unhappy with its length. The article covered sixteen interviews with fashion marketers, each of around 3,000 words, so in total there were nearly 50,000 Chinese characters excluding the introduction and photo captions. Jet pointed out that the layout would be too packed and would not look good according to the chief editor's aesthetic standards. He also criticized my adding shadow and enhancing the colour contrast of photos. He was apparently saying that, as a crucial procedure in strengthening the impact of graphic fashion among readers, photo-retouching must be and could only be "professionally and aesthetically done by the design team." It could never be the territory of an amateur fashion journalist who was supposed to be learning from the good graphical representations of the professionals with whom he was working.

These two episodes reinforce the validity of Jobling (1999)'s emphasis on the power of iconic fashion and vividly portray the organizational socialization process at work in producing a fashion magazine. At Stylistic $X$, fashion writing was at times superseded by graphic representation, in contrast with the way Diana Vreeland cared for the standard of editorial writing in Harper's Bazaar and Vogue (McNeil and Miller, 2014, p. 107), or how fashion critic Suzy Menkes crafted her critical and professional fashion writing in The International Herald Tribune and Vogue (ibid., p. 125). However, later on I also realized that the feature article's sequencing was not simply guided by the fame of featured fashion brands as suggested by Cello, or by the aesthetic harmony stressed by Jet. Rather, it implicitly followed these featured fashion brands' previous (and potential future) ad spends in Stylistic $X$, something 
that was quite noticeably socialized amongst both editorial and graphic design personnel. For instance, local multi-label distributors Joyce Boutique, Lane Crawford, Harvey Nichols, and I.T. Apparel, which have large aggregate advertising budgets to advertise the hundreds of individual fashion labels they sell, were perceived as deserving a more prioritized position (Tse, 2014, pp. 37-38). International luxury brands such as Fendi, Piaget and Van Cleef and Arpels, received double-page layouts, in a secondary prominent position. Remaining brands such as Diesel, Guerlain, Loewe, MCM, and Marc Jacobs, which did not advertise a lot and were deemed as "less important advertisers", were featured in a much less prominent position, each as a one-page coverage in the middle and ending pages of the editorial feature (Tse, 2014, p. 38).

Cello reiterated a few times during the period of observation that visual impact should be of utmost importance. As a specific example, he insisted that all products must display their shadows on the right hand side at an oblique angle (to create a three-dimensional visual effect).

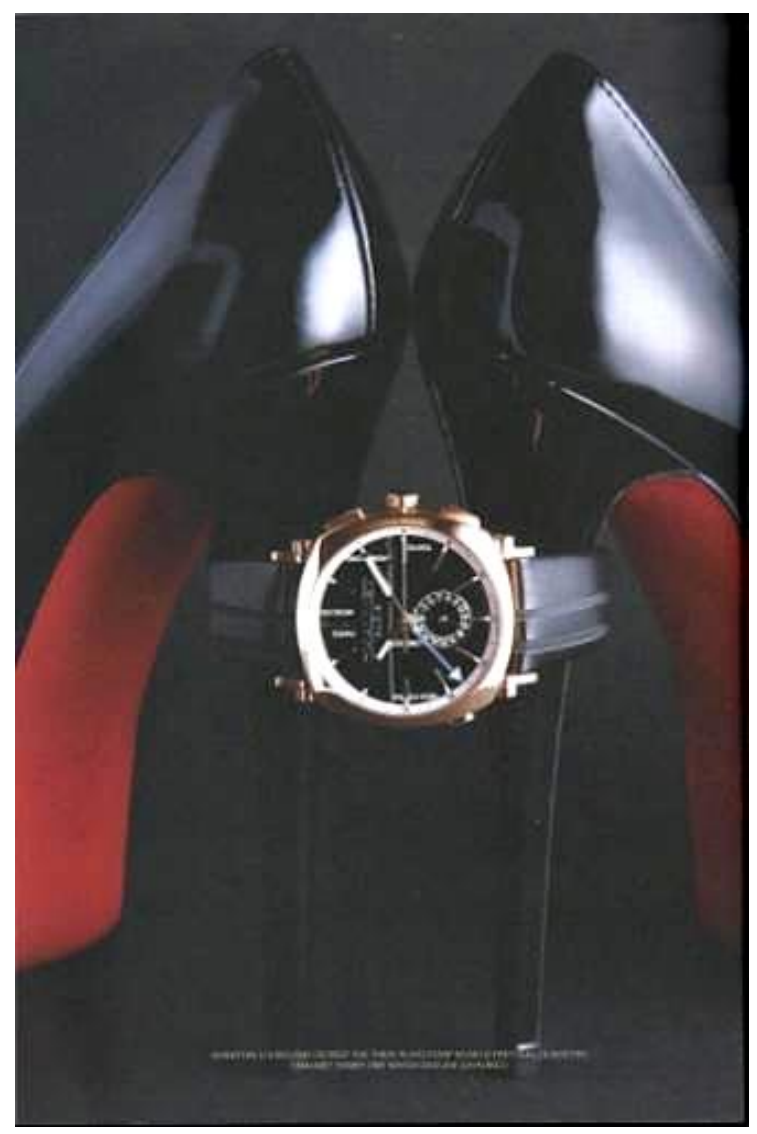




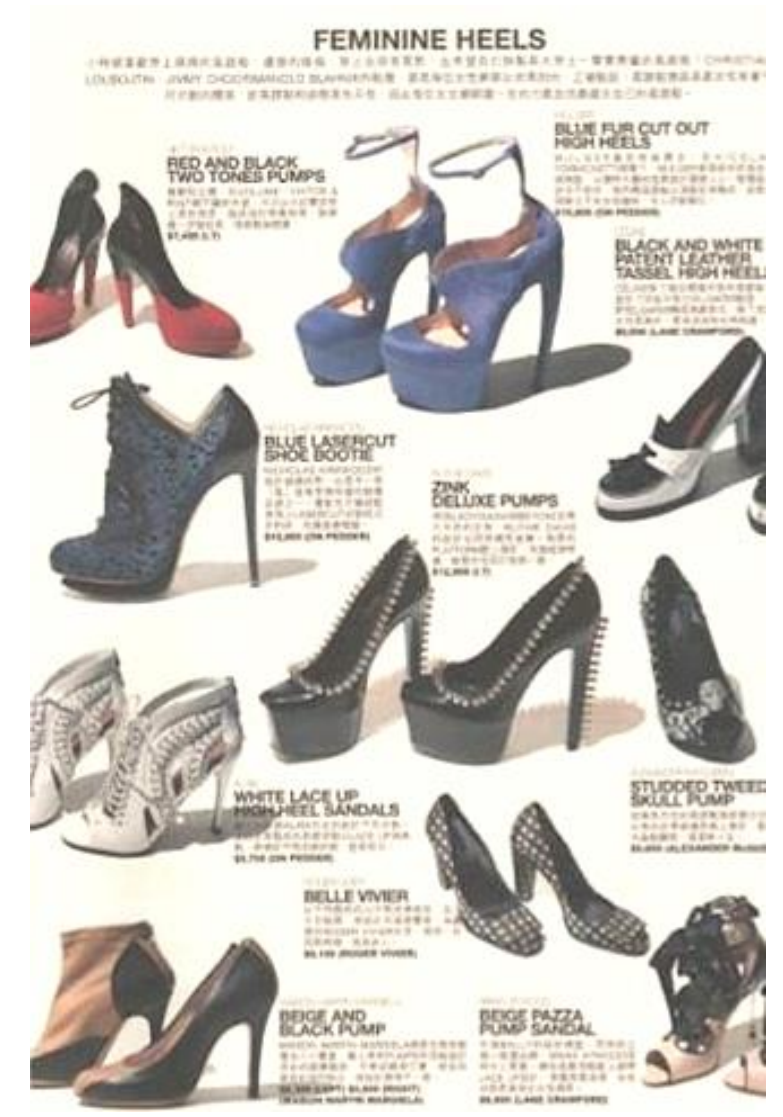

Figure 2. Example of Kris's product styling. Red-lacquered soles of Christian Louboutin and other branded high heels.

Kris later explained that, for instance, a voluminous feeling should always be highlighted when shooting shirts and trousers. The two hems of a pair of trousers should not overlap. The strap of a handbag should be suspended. Shoes must be shown at a 45 degree angle with their shadows on the right hand side to highlight their eye-catching features, patterns and details. Figure 2 illustrates these principles in an ad for the red-soled shoes of Christian Louboutin. The aesthetic wisdom is to maintain consistency, as Kris repeatedly emphasized. She regarded Cello's visual guidelines as unique, but very Japanese-influenced (in its minimalist and tone-on-tone style; abundant white space; mainly using white, grey, beige and other pale-colour palettes instead of other sharply contrasting colours), culturally "odourless" (Iwabuchi, 2006), and quite troublesome to implement. This illustrated the fact that the iconic fashion was highly valued by the chief editor, who imposed his aesthetic preferences and fashion style deemed appropriate for Stylistic $X$ in order to differentiate itself from other international titles in Hong Kong with an "Asian" or "nonWestern" twist. Rather than strictly adopting Euro-American notions of fashion, he applied Japanese aesthetic standards as the primary artistic direction of the magazine. The encoding process involved a more complicated appropriation and negotiation. In the case of Kris's product styling, placing the branded, flamboyant heels on a Japanese-styled 
evacuated white background demonstrated a dramatic shift of artistic direction through the Parisian and Japanese styles. Although a certain degree of flexibility was allowed, the process was still systematically governed by habits acquired within the organization.

\section{Fashionability as a relative concept}

The chief editor's feedback on the ideas presented at editorial meetings suggested that, instead of clearly separating advertising material and advertorials from textual matter, Stylistic $X$ presented many (if not all) of its fashion editorials in a shopping guide format-highlighting product styling features and unambiguously providing tips on what to buy and wear, through a mechanism not simply driven by cyclical fashion trends and aesthetic judgement, but also by the magazine's prioritized commercial relationships with its major advertisers. The magazine aspired to tell of "new" fashion trends in clothing, accessories, and housewares, ascribing luxury meaning to the patterns and designs of its advertisers' seasonal merchandise through a bricolage of texts and visuals in its editorial pages, although many of them were not typically regarded as luxury fashion products. This, Cello felt, would create novelty and address the target readers' main interest, apparently not realizing that this approach logically contradicted his cherished ideas about the true essence of luxury fashion-a cultivated mindset of connoisseurship and subtlety, rather than just materialist consumption. His comments showed how the fashion media institutionally strived to manufacture a consistent order of Stylistic $X$ fashionability and quasi-newness ready for consumption; yet its meanings became elusive and inconsistent amid its interplay with various fields, such as market dynamics and various advertisers' interests.

Ideas about what was considered unfashionable came from casual daily conversations with various Stylistic $X$ co-workers. Among the magazine's workers, fashionability was a relative concept. Bee, the junior copyeditor from the custom project team, prepared an advertorial for an American sandal brand. When packs of brand new sandals arrived for a photo shoot, Bee criticized them as "too dazzlingly colourful... I just don't like them." But her custom editorial feature in the next issue commended them as "beautiful and trendy items for the new season." On another occasion, Jet picked up a scarlet clutch and sarcastically mocked it: "Well, this bag simply has no linkage with the words beautiful and luxurious!" While it could have been just Jet's opinion, Bee and Timothy just smiled, and neither seemed to disagree with him. In a subsequent issue, Stylistic $X$ featured a specific range of handbags in an advertorial, praising them as "elegant, chic and colourful." The above cases show the fluidity of fashion meanings - the complicated assemblage of a range of visual, textual, physical, and psychological elements in fashion photography for the sake of aestheticizing a seasonal product for the summer sales. When it came 
to sponsorships, advertorials, and custom projects, the senior managers took the lead in deciding whether or not to accept a project. Importantly, what was produced as fashionable in the media as a means to target its specified market segments did not necessarily reflect the personal taste and inner thoughts of the producer, from whom a typical fashion magazine reader would have liked to seek professional and aesthetic advice. Those who produced the copy had no control. They were socialized into manufacturing and maintaining a kind of Stylistic $X$ visuality.

Fei, the 28-year-old fashion editor-tastefully dressed in her longsleeve black T-shirt, black leggings with an eye-catching red floral-print dress on top and black leather gladiator shoes-was one who, without any structured questioning, expressed discontent with her current career and the Hong Kong fashion media scene. As an example, she cited a campaign featuring a well-known but middle-aged Hong Kong singer, Sandy Lam, on an international fashion magazine's cover. Fei severely criticized the hair style and make-up of the star as making her look "weird and ugly." I asked if the problem was in the retouching, but Fei responded:

"The truth is, Sandy can never appear in such a Lady Gaga style, with her 'wet' look and heavy make-up in a bold and sexually seductive posturing. In one photo she put on a one-piece dress made of see-through fabric on the upper chest area, and in the other she wore a V-neck, low-cut, glitzy and body-revealing evening gown. She's way too 'oriental' to fit in this style. It was probably the responsible fashion stylist's intention, but she looks bewitched. She can look good only in a clean and simple style. Of course, she's famous and a good singer, but that doesn't mean she can be playfully styled in all sorts of different looks."

Fei's criticism of the insensitive and crude presentation of Sandy Lam in an international fashion magazine as unstylish, inelegant, vulgar, and anachronistic went along with the Stylistic $X$ aestheticism in which she was deeply socialized. Her comments also implied that age, facial appearance, body shape, ethnicity, and associated cultural style all affected a celebrity or model's suitability for representing particular fashion aesthetics. According to Mears, it is crucial that celebrities or models, as "material signifiers" of fashion (2014, p. 1331), aesthetically fit the brand or style in order to communicate "the classed culture of the organization" (ibid.), and to instill a competitive edge in fashion retailers. This indicates that one should not regard the fashion media industry as a purposeful, unified apparatus which unthinkingly manufactures cyclical fashion trends. On the industrial and organizational level, fashionability is generated and sustained through the articulation and maintenance of fashion media publications' respective market positions; the entrance, exit, and merger of media organizations; the ideal target audiences they intend to reach; and a gradually changing network of advertisers and 
sponsors with whom they ally themselves. It is rather simplistic to think that their power in encoding fashion relies solely on their financial strength. The industry itself can be pluralistic and dynamically generate a variety of styles to gratify the increasingly segmented markets and customers' needs.

And this mutuality of fashion meanings among the agents, organizational and industrial structures elucidates the reason why it is futile when one attempts to uncover a systematic set of aesthetic criteria to evaluate whether Stylistic $X$ and its employees were conveying a consistent set of fashionability, and it was not difficult to find counterexamples in previous Stylistic $X$ issues, and in each employee's judgments at work and in their everyday lives, so that the only consistent fact was their overall consistent inconsistency. Iconic fashion elements presented in Stylistic $X$ - such as preferred colour schemes and aesthetic styles-were not being consistently articulated or maintained, and it was not really about the diverse backgrounds and conflicting aesthetic preferences of various fashion journalists, but a constant change of collaboration with an extensive range of fashion and non-fashion advertisers available in the local market, and a constant competition with other media vehicles that were also perceived to be able to convey intended fashion messages to their ideal target segments. Eventually, new ways of coordinating a myriad of textual and visual fashion representations were produced approximating to the imagined taste and profile of a constructed readership. At the same time, the magazine's (symmetrical) graphic design and grid, its typeface and point, superficially maintained an aesthetic consistency despite the broad range of colours, silhouettes, and materials being presented. The documentary film The September Issue (Cutler, 2010) portrayed the constant disagreements between Vogue Editor-in-Chief Anna Wintour and her Creative Director Grace Coddington over which aesthetic styles and visual presentations were and were not fashionable. Their debate spanned thirty years. It seems that fashion journalists can never make an accurate guess about what the editor-inchief really wants and his or her aesthetic guidelines in any consistent way. The encoders work from no such common code book, and their sense of fashionability is constantly shaped and reshaped by the updated list of advertisers and socio-cultural changes at large.

\section{What makes a physical item fashionable or unfashionable?}

What caused physical objects to be regarded as fashionable by Stylistic X? Taking the items featured in the magazine as examples, we can see that there was an endless list of "lifestyle" goods which qualify. The selfprofessed high fashion magazine discussed splendid interior decorating items, delicate Western cuisine, glittering evening gowns, but also ecofriendly hiking outfits, feather hats and sportive caps, hobo bags, clutches, sneakers, and high heels. The fashion journalists could juggle with a wide 
range of items as long as they could line them up with the world of fashion tactfully and, importantly, could convince the chief editor that their ideas went well with the magazine's positioned fashionability. Apparently, for a publication specializing in fashion and aimed at educating consumers about the idea of real luxury, it seemed unlikely that a feature on hiking outfits would have higher priority than one on the historical development of Western fashion design. Situating the production logic of fashionability within the symbiosis of media and advertising unearthed an otherwise invisible network. Kim was assigned to tag specific hiking products of a sponsoring brand in a lighthearted outdoor activity feature, whereas Kris's suggested feature story about fashion history was regarded as "not an urgently needed topic." The difference was that Kris's feature was not sponsored by any specific brand. This episode shows that, as might be expected, commercial interests frame a professional and seasoned judgment about what is fashionable. Fashion is always commercial; yet different forms of commercial alliance fabricate different sorts of fashionability.

Among the preset eleven categories of "Stylistic $X$ ingredients," the special features, lifestyle, trendy items, and other custom-made project categories are the most flexible for directly or indirectly featuring advertised products and services which may or may not apparently relate to the notion of fashion. Yet there are exceptional cases too. According to Sally, the Sales Director of Youth Style, sponsorships by advertisers of body slimming, liposuction, and breast implant surgery would never be accepted by any of the company's fashion publications under any circumstances. Some regarded such services as part of a contemporary worldwide trend toward fashioning one's physical body; many other fashion publications were more than happy to include such advertisements. But owners of Youth Style and Stylistic X regarded them as harmful and unethical, and that made them "unfashionable." More crucially, they were perceived to be graceless and untasteful in the eyes of the magazine's major advertisers and desired luxury consumers. The specific ethic strictly upheld by the media organization thus interplayed with the preferences of its advertisers and consumers once again. Although its fundamental goal must be to make a profit and stay in business, a one-dimensional viewpoint would suggest that other nonmonetary objectives were simultaneously embraced to help establish a sense of professionalism. Yet it seems more convincing to see the exclusion of such sensitive advertisements as a protection of the fashion publication's unique sense of "real" luxury and fashionability, and its ongoing commercial partnership with major advertisers-a concrete example showing how the "editorial text versus advertising" tension in a fashion magazine was played out.

The definition of "luxury" is a particular conundrum. Is deluxe status based solely on price, exclusivity of the materials, or some other quantifiable factor? In reality, prestigious fashion brands like Jimmy Choo, 
Versace, and Lanvin consider cooperating with the Swedish street fashion brand H\&M in launching a budget priced "affordable luxury" collection, resonating with the emerging "masstige" motto-the mixture of "mass" and "prestige" to propagate the new luxury for masses (Silverstein and Fiske, 2003, pp. 48-57; Von Maltzahn, 2015). Exuding high-end brand appeal, yet affordable at a price level "just above the average" (Von Maltzahn, 2015, p. 1), this democratized form of luxury has rendered itself accessible to all, expanding a firm's customer base exponentially at the cost of the lowered exclusivity of its products.

Shifting market factors have also attributed to the devaluing of the concept of luxury: the rise of the new markets and media has led to destratification of consumer segments, thereby propelling changes in tastes and consumer behaviour, and blurring the "definition of true luxury" (Von Maltzahn, 2015, p. 3). In frequent conversations, the chief editor shared his conception of the spirit of luxury. He conceived of Stylistic $X$ as presenting real luxury, defined not just in terms of price, but also by image. He literally asserted that "fashionability is not just about materials and affordability, but also a cultivated mindset of connoisseurship, understatement, and subtlety. This is the true spirit of luxury which nowadays many teenagers and young consumers do not realize that even they can afford. Stylistic $X$ exists to educate these people." In other words, the abstract, refined, yet esoteric, sense of taste Cello so splendidly described constituted a vibrant deployment of Bourdieu's (1984) notion of cultural capital in the contemporary materialist world-learning about the fashion news and familiarizing oneself with particular luxury fashion imagery by reading Stylistic $X$ enriched one's cultural capital, and socialized one to believe that $s /$ he was appreciating luxury in a distinctively superior manner, while simultaneously distinguishing one's self in the world.

Stylistic X fashionability: associated only with certain firms and institutions?

Surely there was no clear definition of, or guidebook to, fashionability, but in their daily work media personnel adhered to an unspoken yet concrete paradigm. They often automatically referred to certain brands whenever they spoke of luxury fashion or high fashion. At Stylistic X, Chanel, Christian Dior, Fendi, Giorgio Armani, Gucci, Hermès, Louis Vuitton, and Prada, all ostensibly French or Italian, were the automatic referents. They all presented different design concepts, styles and materials, as well as product specializations, but all were affiliated with the largest and financially strongest global fashion conglomerates which could make huge investments in international advertising and promotion. This recalls what Chevalier and Mazzalovo (2008) described as a powerful tactic of many global fashion marketers in historicizing their brands, enhancing their global visibility, and reinforcing their fashionability among their target 
segments. And the alternative, subversive brands that Evans (2003) suggested were supposedly influential in the fashion world today were in fact not so highly regarded by those in the fashion media-at least not when they were pragmatically anticipating their wearability for, and impact on, their target audiences.

Stylistic X's editorial, copywriting, and design personnel regularly and habitually flipped through a range of Western and Japanese fashion and design magazines for conceptual inspiration, as well as for design layout references. If fashion is a religion, these magazines are its bibles, reinforcing the paradigms. They borrowed and circulated the magazines constantly. As Kris explained: "We all know that fashion magazines like SoEn (Japanese), Vogue (American), L'Officiel and Elle (French) are classic and authentic fashion media. They always capably and powerfully represent the 'true' fashion [paradigm]." During fieldwork, it took time for me to learn the rules of inclusion and exclusion. This I did by flipping through the back issues of Stylistic $X$ and studying previously featured brands. The more frequently and extensively a brand had been featured and advertised, the more voguish and significant it seemed to be. Fashionable labels were commonly affiliated with fashion conglomerates like the LVMH or Kering Group. Price range and degree of perceived luxury were positively correlated in most cases. Origin (France, Italy or Britain) was also important. Technically, non-mainstream yet prestigious brands (like the Belgian Martin Margiela and the British/Turkish Cypriot Hussein Chalayan) would still be occasionally featured in the "special features," "fashion", "trendy items," "design and art," and "events" coverage, but it was very rare for them to be featured as a "cover story" or a custom-made project with prominent and extensive coverage, as they could not compete with the big advertisers who bought out the most visible space in the magazine. In Hong Kong, Post Magazine (a weekly magazine inserted in the top English newspaper South China Morning Post on Sundays [Sunday Morning Post]), Marie Claire Hong Kong, and Elle Hong Kong were the titles which did not sell their cover page to a single fashion brand, as it was not necessary financially for them to feature big brands on their cover. Nonetheless, it was essential for fashion magazines, amongst all other types of media businesses, to generate profit in order to survive in the commercial world. Following the rise of digital technology and social media, the worldwide magazine industry has faced lean times. From 2007 to 2010, its advertising revenue fell around fifteen percent; magazines also started offering ancillary services including e-commerce, custom publishing, and joint-event promotion, as well as database assistance, to generate new sources of revenue (Dominick, 2013, p. 152).

It became apparent that fashion is being defined through a process of organizational and industrial socialization, which to some extent theoretically contradicts the chief editor's concept of real luxury discussed earlier, but which is more in tune with the advertising revenues paradigm. Cello indirectly expressed his view that some brands affiliated 
with the LVMH Group were in fact not treated as luxurious and fashionable because they would be unable to appeal to the magazine's audience or fit with its other content. For Cello, it seemed, luxury and fashionability were in the eye of the beholder. In reality, it was more about which brand (instead of what fashion) was fashionable and luxurious: it mattered more about these fashion brands' marketing activities in Hong Kong, their advertising budgets, and the possibility of collaboration with Stylistic $X$.

Stylistic X fashionability: agents, culture, history and social class

Cello always insisted that Stylistic $X$ is about "real" luxury, highlighting subtlety, details and delicacy, which he believed other local fashion magazines did not truly care about and could not accurately represent.

"Stylistic $X$ is a fashion magazine [presenting taste] young people are not usually interested in...[It is] linked with history and an historical aura-about eternal beauty rather than merely about the avant-garde... Not only focused on celebrity endorsements, as they can be very superficial... [The magazine] can be treated as a fashion encyclopedia to be collected and read over a long period of time."

In Cello's mind, fashion has an "authentic" history that would interest the magazine's target readers, who are not young, superficial consumers who do not know how to appreciate luxury fashion. Nevertheless, certain of the editorial and copywriting staff to some extent adopted the aesthetic styles displayed in American, Parisian, British and Japanese fashion magazines and on their websites.

Paradoxically, most Stylistic $X$ staff apparently saw themselves as gatekeepers, but did not necessarily perceive a need to have a strong personal interest in high fashion. Personal interest in fashion was not common among the staff. The editorial and copyediting team had a large proportion of people younger than 25 who did not really appreciate or consume luxury fashion themselves, if only because they just could not afford it. Among the entire Stylistic X staff of 23 persons (eight male/fifteen female), ${ }^{7}$ Fei, Kris and Jet were the only three who explicitly demonstrated a personal interest in fashion both at work and in their everyday lives. In general, the others were neither overtly model-fit nor especially attractive physically. Timothy and Kim even expressed their personal indifference to, and disinterest in, luxury fashion. Cello and Sporty, the two seasoned editorial team heads, were in fact regarded by the junior staff as very unfashionable. Kim, Kris and Jet secretly mocked Sporty's and Cello's looks, suggesting that they actually looked more like athletes or journalists of Sports World, a local television programme, than stylish fashion editors. In the eyes of their Stylistic $X$ co-workers, the

${ }^{7}$ Refer to Appendix 1 
senior staff (Cello, Sporty, Tribecca and Tina) were not necessarily seen as more fashionable or as having a superior understanding of fashion. Certainly, this was not intended to denigrate their work, but it was in distinct contrast with the magazine's positioning and with the glitzy image of senior fashion journalists.

\section{Conclusion}

Viewing the case of Stylistic $X$ through participant observation reveals clashing fashion meanings in the collective encoding and representation processes taking place in the fashion magazine industry. As Moeran (2015, p. 144-146) has described in his ethnographic research on Japanese fashion magazines, written clothing, as Barthes asserted, consists of a large number of free-floating signifiers, and the lexical structure of the fashion discourse is more unstable when compared to those of similar evaluative discourses in the fields of aesthetics and wine. Different fashion media personnel, and sometimes the same person on different occasions, apply contradictory rules in determining what is and is not fashionable in written, tangible, intangible, and iconic presentation, based on the 'evaluative terms' benchmarking Stylistic X fashionabilityluxurious, understated, cultivated and timeless. These keywords, "imbued with multiple condensed meanings, while at the same time being lexically and syntactically predictable" (Moeran, 2015, p. 151), are promiscuously used by people in and around the fashion world who believe they agree on their 'meanings'. Association with specific companies, people, cultures and nations is often adopted as a shorthand in defining fashion's meaningsespecially in iconic presentation. This apparently resonates with Jobling (1999)'s proposed power of iconic fashion; yet its fundamental logic lies in the objective of profiling ideal target consumers to appeal to a diverse range of existing and potential advertisers (Moeran, 2015). Episodes exemplifying the ideas of the critical school of fashion theorists certainly were observed. Intentionally or unintentionally, a range of random, cyclical, and inconsistent fashion meanings were consistently adopted ("Five Dichotomies in Menswear Fashion," "Old but Beautiful," and "Hiking Outfits," for example). At times fashion editorials were presented in shopping guide format, rather than as critical and professional comments on fashion trends and styles, and were intended simply to trigger consumption. Fashionability generated in the observed Hong Kong magazine was closely linked with capitalist evaluation criteria-such as its monetary value, the financial power of the brand, and its advertising budget. Items not normally considered fashionable like hiking outfits, candles, and sandals could be tactfully fused with fashionable meanings in the right season through rhetoric, description, and visual portrayals, as well as by means of sponsored advertorial coverage, even replacing editorial topics indisputably related to fashion.

In general, the media personnel observed, ostensibly fashion 
mediators, did not seem very powerful in manipulating the encoding process. This does not mean that fashion meanings are rigidly prescribed, nor that media workers could not influence fashion meanings at all. Some fashion media personnel were observed criticizing or mocking those fashion meanings they saw as deviating from "Stylistic $X$ fashionability." They expressed their personal tastes and aesthetic sense in order to differentiate their superior fashion-selves from those at other companies, or of different nationality, or simply to display their unique academic, social, cultural and historical background-"as a means of displaying their membership of that [fashion] world on the one hand, and their exclusiveness vis-à-vis outsiders on the other" (Moeran, 2015, p. 152). The most vivid instance of this was the way Cello mystically defined luxury fashion as a cultivated mindset of connoisseurship, understatement and subtlety unreachable by most youngsters and mainlanders, yet so obvious to the cultured eye. The evaluative term "luxury" was subject to multiple elucidations between different fashion brands and cultural contexts, depending on "who uses it, to and about whom, and in what context" (ibid.). Overall, observation demonstrated that fashion meanings are encoded in a non-linear and continuously inconsistent way. The encoding process did involve aesthetic and creative judgments, although more often it relied on capitalist benchmarks through organizational and industrial socialization processes.

A few of the media workers observed were personally passionate about fashion, and able to demonstrate and articulate their preferred and pluralistic senses of fashion, whether Japanese minimalist style or EuroAmerican glamour. This seems to disagree with the critical perspective that fashion consists purely of an unaesthetic, drifting and "vulgar" taste. The continuous monitoring of fashion meanings throughout the encoding process-from Cello's comments on graphical layouts to Jet's principles in retouching of fashion images-did not help facilitate consistency in encoding fashionability. In reality, the researched magazine had to survive by collaborating with a variety of fashion and non-fashion advertisers, whose brand identities, products and services might or might not match the ideal Stylistic $X$ fashionability-representing the tastes and lifestyles of their readers - at once aspired to and simulated by the magazine's media personnel. On an industry level, such an encoding process also involved competition with other major players in the local market, from local fashion magazines to international fashion titles, to other media organizations, all trying to siphon off the limited aggregate luxury fashion ad spends of the advertisers who are always in high hope of catching the eye of their imaginary luxury consumers. On a monthly basis, a new yet dissimilar blend of fashion and non-fashion products and brand messages becomes the resources and ingredients for media staffers to manufacture Stylistic $X$ fashionability, which was one significant reason why they manifested contradictory fashion meanings at different times, visually and textually, thereby perpetuating "consistent inconsistency". 


\section{References}

Aspers, P., and Godart, F. (2013). Sociology of fashion: Order and change. Annual Review of Sociology, 39, 171-192.

Barnard, M. (1996). Fashion as Communication. London: Routledge.

Barthes, R. (1990). The Fashion System. Berkeley: University of California Press.

Baudrillard, J. (2007). Fashion, or the enchanting spectacle of the code. In Malcolm Barnard (ed), Fashion Theory: A Reader. London: Routledge, pp. 462-474.

Becker, H. S. (1984). Art Worlds. Berkeley: University of California Press.

Blumer, H. (1969). Fashion: From class differentiation to collective selection. Sociological Quarterly, 10(3), 275-291.

Bourdieu, P. (1984). Distinction: A Social Critique of the Judgment of Taste. London: Routledge and Kegan Paul.

Caves, R. E. (2003). Contracts between art and commerce. Journal of Economic Perspectives, 17 (2), 73-84.

Census and Statistics Department, the Government of Hong Kong Special Administrative Region (2015). Retrieved November 12, 2015, from http://www.censtatd.gov.hk/home/.

Chevalier, M., and Lu, P. X. (2009). Luxury China: Market Opportunities and Potential. Singapore: John Wiley and Sons.

Chevalier, M. and Mazzalovo, G. (2008) Luxury Brand Management: A World of Privilege. Singapore: John Wiley and Sons (Asia).

Crane, D. (2000). Fashion and its Social Agendas: Class, Gender, and Identity in Clothing. Chicago and London: University of Chicago Press.

Croteau, D. (2003). Media/Society: Industries, Images, and Audiences (3rd ed). Thousand Oaks, CA: Pine Forge Press.

Cutler, R.J. (2010). The September Issue (film). Burbank, CA: Lionsgate.

DeWalt, K.M. and DeWalt, B.R. (2002). Participant Observation: A Guide for Fieldworkers. Walnut Creek, CA: AltaMira Press.

Dominick, J.R. (2013). The Dynamics of Mass Communication (12th ed). New York: McGraw-Hill Higher Education.

Entwistle, J. (2000). The Fashioned Body: Fashion, Dress and Modern Social Theory. Cambridge: Polity Press.

Evans, C. (2003). Fashion at the Edge: Spectacle, Modernity and Deathliness. New Haven, CT: Yale University Press.

Ferguson, M. (1990). Images of power and the feminist fallacy. Critical Studies in Media Communication, 7 (3), 215-230.

Iwabuchi, K. (2006). Japanese popular culture and postcolonial desire for 
"Asia." In Matthew Allen and Rumi Sakamoto (eds), Popular Culture, Globalization and Japan. London and New York: Routledge, pp.15-35.

Jobling, P. (1999). Fashion Spreads: Word and Image in Fashion Photography since 1980. Oxford: Berg.

Kawamura, Y. (2004). Fashion-ology: An Introduction to Fashion Studies.

Oxford: Berg.

Lea-Greenwood, G. (2013). Fashion Marketing Communications. Hobken: John Wiley and Sons.

Leung, L. (2004). Fashioning (Western) sexuality for sale: The case of sex and fashion articles in Cosmopolitan Hong Kong. In Chan Kit-wa and Wong Wai-ling (eds), Gendering Hong Kong. Hong Kong: Oxford University Press, pp. 420-441.

Massoni, K. (2004). Modeling work occupational messages in Seventeen Magazine. Gender and Society, 18 (1), 47-65.

McNeil, P. and Miller, S. (2014). Fashion Writing and Criticism: History, Theory, Practice. London; New York: Bloomsbury Academic.

Mears, A. (2014). Aesthetic labor for the sociologies of work, gender, and beauty. Sociology Compass, 8 (12), 1330-1343.

Moeran, B. (2015). The Magic of Fashion: Ritual, Commodity, Glamour. Walnut Creek, CA: Left Coast Press.

Oliveira, P. (2012). Ethnography and co-creation in a Portuguese consultancy: Wine branding research as an example. Journal of Business Anthropology, 1 (2), 197-217.

Silverstein, M. J., and Fiske, N. (2003). Luxury for the masses. Harvard Business Review, 81 (4), 48-57.

Simmel, G. (1957). Fashion. American Journal of Sociology, 62 (6), 541558.

Steele, V. (2005). Encyclopedia of Clothing and Fashion. New York: Thomson/Gale.

Tse, T. (2014). Negotiations between fashion marketers and journalists in Asia. Asian Journal of Business Research, 4 (1), 30-42.

Tse, T. (2015). Two different tales of fashion media industry development in Mainland China and Hong Kong. Clothing Cultures, 2 (3), 257-274.

Vangkilde, K. T. (2011). A funky-formal fashion collection: Struggling for a creative concept in Hugo Boss. The Journal of Business Anthropology 3 (2), 1-17.

Von Maltzahn, C.F. (2015). The long way home: Luxury and its discontents. Paper presented at Fashion Tales, Università Cattolica del Sacro Cuore, Milan.

Wilson, E. (2007). A note on glamour. Fashion Theory, 11 (1), 95-108. 
Dr. Tommy Tse is an Assistant Professor at the Department of Sociology, The University of Hong Kong. He specializes in Asia's cultural industries and sociology of fashion. His work has appeared in Asian Journal of Business Research, International Journal of Fashion Design, Technology and Education, Clothing Cultures, International Journal of Fashion Studies and Young Consumers. Previously, Tse worked in various media and creative companies, and also taught at the School of Communication, Hong Kong Baptist University; Central Saint Martins, University of the Arts London; the Culture and Media Domain, HKU SPACE; and Hong Kong Design Institute. 


\section{Appendix 1}

Organization Structure of Stylistic X

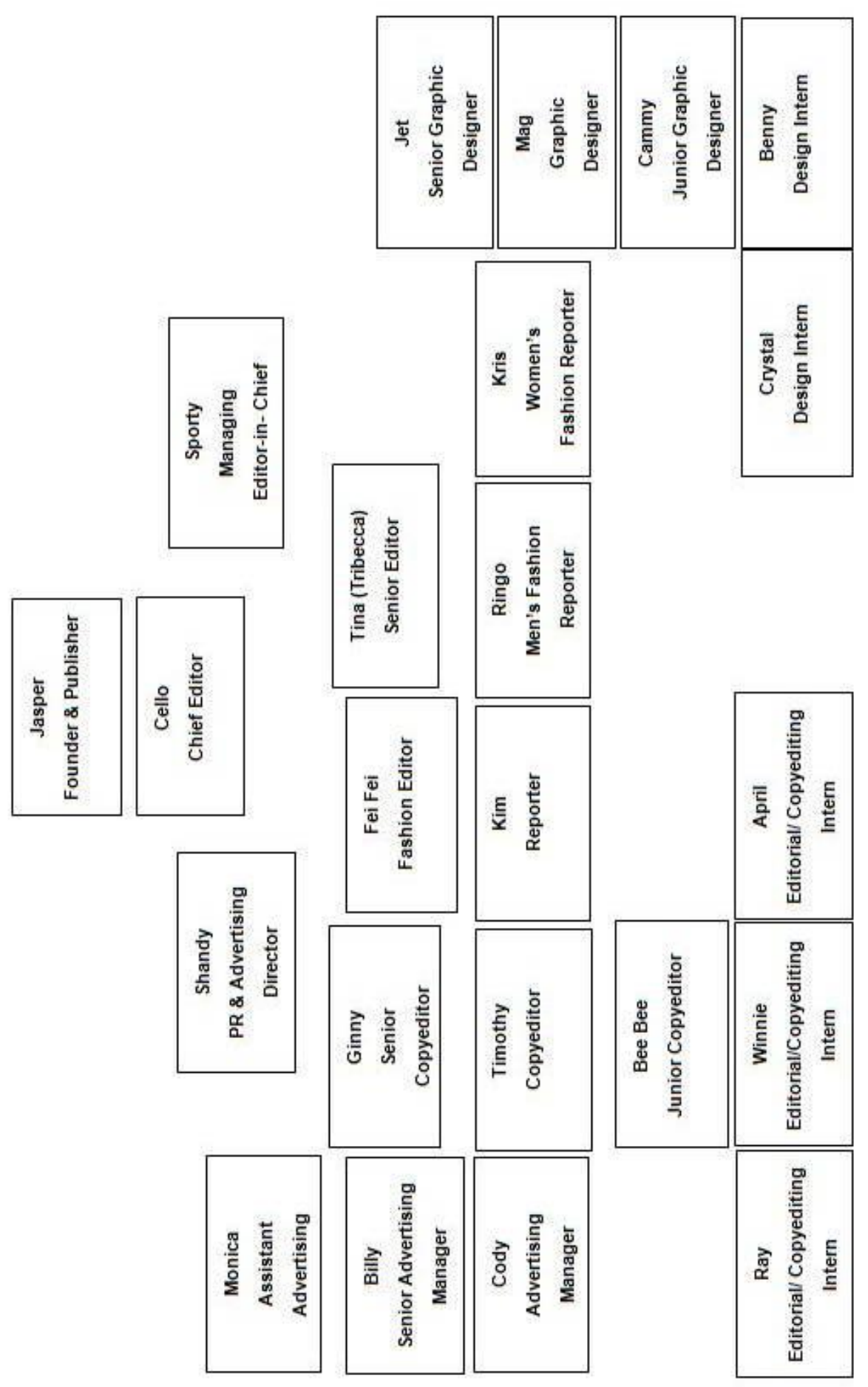

